\title{
Prevalence of dermatoses and skin sensitisation associated with use of pesticides in fruit farmers of southern Taiwan
}

\author{
Yueliang Leon Guo, Bour-Jr Wang, Ching-Chang Lee, Jung-Der Wang
}

\begin{abstract}
Objectives-Agricultural workers are known to have occupational skin diseases. The prevalence and pattern of skin diseases are unknown in Taiwanese fruit farmers. The objective of this study is to determine the work exposure, prevalence of skin diseases, and sensitivity to common skin allergens and agricultural chemicals in fruit farmers of southern Taiwan.

Methods-122 fruit farmers who regularly prepared and sprayed pesticides and a group of 63 printing press workers with no known exposure to pesticides were examined and patch tested with common skin allergens and agricultural chemicals. The farmers were also interviewed for their work habits, use of protective clothing, and exposure to pesticides.
\end{abstract}

Results-Most farmers reported regular use of hat, boots, and mask, but not gloves, raincoat, and goggles. This resulted in frequent skin contact with pesticides especially on the hands and face. About $30 \%$ of farmers had hand dermatitis, and more than two thirds had pigmentation and thickening on the hands. Fungal infection of the skin was noted in a quarter of subjects. By patch test, farmers and the printing press workers had a similar rate of sensitivity to common skin allergens. $\mathbf{4 0} \%$ of farmers were sensitive to agricultural chemical allergens, which was about twofold higher than that of the comparison group. Farmers were most frequently sensitive to Captofol, Folpet, and Captan which were associated with dermatitis on the volar aspects of the hands.

Conclusions-Fruit farmers in southern Taiwan had a high prevalence of skin diseases related to use of pesticides, and appropriate protective measures and work practices should be taken to prevent such problems.

\section{(Occup Environ Med 1996;53:427-431)}

Keywords: dermatitis; fruit farmers; agricultural chemicals

In agricultural workers, occupational skin disease has been one of the most important occupational diseases and has been reported more frequently than in non-agricultural workers. ${ }^{1}$ Although the precise incidences and prevalences of skin diseases related to pesticides are unknown, the agricultural sector was noted to have the highest rate of occupational skin disease of any industry in California, which was twice the rate of the manufacturing sector. ${ }^{1}$ Agricultural chemicals-especially pesticides, plant and animal products, soaps, detergents, and cleaners were among the most important causes of occupational skin diseases in farm workers. Pesticides are widely used in agricultural and non-agricultural settings in Taiwan. In 1992, an estimated total of 36000 tonnes of pesticides was used on 360000 hectares of agricultural land in Taiwan, therefore pesticides were used at the rate of about 100 $\mathrm{kg} /$ hectare/year. With more than 800 active ingredients in use, the range of adverse effects of these chemicals is diverse, and a large proportion involve the skin. For example, about one quarter of reported illnesses and injuries caused by pesticides in California were dermatological. ${ }^{2}$ The incidence of skin disease related to pesticides in Taiwan, although not known, is expected to be high for the following reasons: (a) the amount of pesticides used per unit area in Taiwan has been high; $(b)$ many pesticide users are often unaware of the adverse effects of pesticides on human health, ${ }^{3}$ and do not strictly follow the instruction on the proper use of pesticides; and $(c)$ the hot and humid weather discourages farmers from using proper protection.

Although occupational skin diseases in farm workers caused by pesticides might be considerable in Taiwan, there has not been a complete description of dermatological diseases and their relations to use of pesticides. We conducted this study on fruit farmers in southern Taiwan to ascertain the nature of skin problems, and the association between skin diseases and use of pesticides.

\section{Subjects and methods}

In December 1991, we performed a routine physical examination of 302 fruit farmers for the Fruit Farmers' Production Association in Nan-sy, a town that is well known for its fruit production, including star fruit, orange, mango, pineapple, and other fruits. There were a total of 311 farmers in that association, who were usually the heads of the households and were interested in promoting the production and sales of their fruits. These farmers were from six villages near Nan-sy town. In late 1992 , we randomly selected three villages in which a total of 145 farmers were examined in 1991. These farmers, who had regularly applied pesticides, were asked to come back for dermatological examination. A structured 
interview with a questionnaire in Chinese or Taiwanese was used to gather information on medical and occupational history, use and exposure to pesticides, work activities, protective equipment related to pesticides, and symptoms and frequency of pesticide intoxication. Skin diseases were assessed by a dermatologist by questionnaire and physical examination. Photographs of the hands were taken during the examination. Dermatitis was diagnosed if erythema, itching, or scaling was present. Pigmentation and skin thickening were also recorded. The photographs were later reviewed blind for skin diseases and patterns of dermatitis for confirmation of the initial examination. Allergens from the European "standard tray" and 50 substances related to pesticides (Chemotechnique Diagnostic $A B$, Sweden; and Trolab, Canada) were used for patch tests. The agricultural chemicals for which patch testing preparations were not commercially available to us-that is, paraquat, malathion, diethoate, dibrom, carbaryl, and parathion-were purchased as pure chemicals from Chem service, West Chester, USA, and prepared by us. The testing agents were applied to Finn chambers (Epitest, Helsinki, Finland) which were fixed to the upper back with Scanpor tape then secured by $3 \mathrm{M}$ tape. The patches were removed after 48 hours and the sites were examined for evidence of a reaction. The sites were examined again at 72 hours by the same dermatologist. The reading at 72 hours was considered to be positive if the reaction was equal to or stronger than a palpable erythema. ${ }^{4}$ A comparison group of workers from two printing press factories in a neighbouring town were also patch tested. The main work of these factories included printing of textbooks, paper boxes, plastic bags, and other materials. Workers in these factories were exposed to formaldehyde, inks, and other solvents. No known occupational exposure to pesticides could be identified. All subjects gave written informed consent before the examination. The data were analysed by descriptive statistics, and $\chi^{2}$ test with the SAS package.

\section{Results}

In total 137 fruit farmers (94.5\%) and 79 printing press workers had the interview and examination. However, only 122 fruit farmers $(84 \cdot 1 \%)$ and 63 printing press workers accepted and finished the patch tests and were recorded for analysis. Table 1 shows the

Table 1 Demographic data of the 122 fruit farmers and control group (printers)

\begin{tabular}{lcc}
\hline & $\begin{array}{l}\text { Farmers } \\
n\end{array}$ & $\begin{array}{l}\text { Controls } \\
n\end{array}$ \\
\hline Age: & & \\
$10-19$ & 0 & 5 \\
$20-29$ & 0 & 29 \\
$30-39$ & 25 & 18 \\
$40-49$ & 45 & 8 \\
$50-59$ & 50 & 1 \\
$>60$ & 2 & 2 \\
Sex: & & \\
Male & 107 & 42 \\
Female & 15 & 21 \\
\hline
\end{tabular}

demographics of these two groups. The farmer group was older than the printing press workers and had less female workers. None of the 63 printing workers reported exposure to farm work or lived on farms. Among the farmers, $112(91 \cdot 2 \%)$ prepared the pesticides themselves. Table 2 lists the farmers who reported using agricultural chemicals frequently (more than once a month). Eighty nine (72.9\%) farmers always wore a mask and 17 (13.9\%) always wore gloves when preparing the pesticides. When spraying the pesticides, 114 $(93.4 \%)$ always used an extension hose, and only a few used a back pack. Most of the farmers reported "almost always" wearing a hat, boots, and a mask when spraying pesticides, but less than a half wore gloves, and only a few wore a rain coat or goggles when spraying (table 3). One hundred and seventeen $(95.9 \%)$ of the farmers reported considerable skin contact with pesticides during spraying and three $(2.5 \%)$ reported contact during preparation of the pesticide. Table 4 shows the sites of frequent skin contact with pesticide during spraying: upper arm, elbow, forearm, antecubital area, shoulder, chest, upper back, lower back, thigh, leg, and head were reported as frequently contaminated sites in less than

Table 2 Agricultural chemicals reported by fruit farmers as "frequently used" (more than once a month) in the past 12 months before the interview (only chemicals reported by more than $10 \%$ of farmers as frequently used are included)

\begin{tabular}{ll}
\hline & Subjects who reported \\
& frequent use \\
Agricultural chemicals & $n(\%)$
\end{tabular}

Organophosphates:

Insecticides

Methamidophos

Dimethoate

Parathion

Monocrotophos

Chlorpyrifos

Fenthion

Methyl parathion

Phorate

Fenitrothion

$85(70 \cdot 0)$

$64(52 \cdot 5)$

$40(32 \cdot 8)$

$37(30 \cdot 3)$

$35(28 \cdot 7)$

$33(27 \cdot 0)$

$25(20.5)$

$21(17 \cdot 2)$

$16(13 \cdot 1)$

Pyrethroid:

Insecticides:

Cypermethrin

$15(12 \cdot 3)$

$39(32 \cdot 0)$

Carbamates:

Methomyl

Ancozeb

Cabaryl

Carbendazim

Benomyl

Carbendazimmetriam

$13(10 \cdot 7)$

Herbicides:

Glyphosate

Paraquat

$50(41 \cdot 0)$

$69(56 \cdot 6)$

$59(48.4)$

$47(38 \cdot 5)$

$46(37.7)$

$36(29 \cdot 5)$

23 (18.9)

Miticides:

Bromopropylate $28(23.0)$

Cyhexatin

$118(96 \cdot 7)$

$59(48 \cdot 4)$

$28(23 \cdot 0)$
$13(10 \cdot 7)$

* Seven $(5 \cdot 7 \%)$ farmers reported frequent use of Captan five $(4 \cdot 1 \%)$ reported frequent use of Captofol, and none reported frequent use of Folpet.

Table 3 Farmers who reported almost always using protective measures during spraying of pesticides

\begin{tabular}{lc}
\hline Protection & $n(\%)$ \\
\hline Hat & $121(99 \cdot 2)$ \\
Boots & $118(96 \cdot 7)$ \\
Mask & $111(91 \cdot 0)$ \\
Gloves & $44(36 \cdot 1)$ \\
Raincoat & $9(7 \cdot 4)$ \\
Goggles & $4(3 \cdot 3)$ \\
\hline
\end{tabular}


Table 4 Frequently contaminated sites when spraying pesticides as reported by the 122 farmers

\begin{tabular}{lr}
\hline Site & $n(\%)$ \\
\hline Palm & $104(85 \cdot 2)$ \\
Dorsal hand & $103(84 \cdot 4)$ \\
Finger web & $99(81 \cdot 1)$ \\
Face & $94(77 \cdot 0)$ \\
Finger nail & $92(75 \cdot 4)$ \\
Ear & $41(33 \cdot 6)$ \\
Neck & $39(32 \cdot 0)$ \\
Wrist & $37(30 \cdot 3)$ \\
\hline
\end{tabular}

Table 5 Farmers with dermatitis, pigmentation, and thickening of skin (n (\%))

\begin{tabular}{lccr}
\hline Site & Dermatitis & Pigmentation & Thickening \\
\hline Right volar finger & $14(11 \cdot 5)$ & $2(1 \cdot 6)$ & $52(42 \cdot 6)$ \\
Right volar palm & $14(11 \cdot 5)$ & 0 & $38(31 \cdot 1)$ \\
Right dorsal finger & $7(5 \cdot 7)$ & $68(55 \cdot 7)$ & $103(84 \cdot 4)$ \\
Right dorsal hand & $6(4 \cdot 9)$ & $68(55 \cdot 7)$ & $96(78 \cdot 7)$ \\
Left volar finger & $12(9 \cdot 8)$ & $4(3 \cdot 3)$ & $47(38 \cdot 5)$ \\
Left volar palm & $3(2 \cdot 5)$ & 0 & $32(26 \cdot 2)$ \\
Left dorsal finger & $1(0 \cdot 8)$ & $65(53 \cdot 3)$ & $98(80 \cdot 3)$ \\
Left dorsal hand & 0 & $56(45 \cdot 9)$ & $82(67 \cdot 2)$ \\
Tinea pedis & $15(12 \cdot 3)$ & & \\
Tinea vesicolar & $12(9 \cdot 8)$ & & \\
Tinea ungua & $5(4 \cdot 1)$ & & \\
Tinea manus & $2(1 \cdot 6)$ & & \\
Tinea cruris & $1(0 \cdot 8)$ & & \\
\hline
\end{tabular}

$\star$ A total of $37(30.3 \%)$ farmers had hand dermatitis. Some of them had dermatitis at more than one site.

Table 6 Skin sensitisation in farmers and controls (printers) to test agents in European standard tray (comparisons were by $\chi^{2}$ test)

\begin{tabular}{|c|c|c|c|c|c|}
\hline Test compound & $\begin{array}{l}\text { Concentration } \\
(\%) \\
\text { (w/w) }\end{array}$ & Vehicle & $\begin{array}{l}\text { Sensitised } \\
\text { farmers } \\
\text { total } n=122 \\
n(\%)\end{array}$ & $\begin{array}{l}\text { Sensitised } \\
\text { controls } \\
\text { total } n=63 \\
n(\%)\end{array}$ & Pvalue \\
\hline Carba mix & $3 \cdot 0$ & pet & $9(7 \cdot 4)$ & $3(4 \cdot 8)$ & NS \\
\hline Frangrance mix & $8 \cdot 0$ & pet & $7(5 \cdot 7)$ & $1(1 \cdot 6)$ & NS \\
\hline Potassium dichromate & 0.5 & pet & $6(4.9)$ & $3(4 \cdot 8)$ & NS \\
\hline Balsam of Peru & $25 \cdot 0$ & pet & $2(1 \cdot 6)$ & $1(1 \cdot 6)$ & NS \\
\hline Cobalt chloride & $1 \cdot 0$ & pet & $2(1 \cdot 6)$ & $2(3 \cdot 2)$ & NS \\
\hline Nickel sulphate & $5 \cdot 0$ & pet & $2(1 \cdot 6)$ & $5(7.9)$ & 0.03 \\
\hline Formaldehyde & $1 \cdot 0$ & $\mathrm{aq}$ & $1(0 \cdot 8)$ & $3(4 \cdot 8)$ & 0.08 \\
\hline Colophony & $20 \cdot 0$ & pet & $1(0.8)$ & $2(3 \cdot 2)$ & NS \\
\hline Epoxy resins & $1 \cdot 0$ & pet & $1(0 \cdot 8)$ & $1(1 \cdot 6)$ & NS \\
\hline Neomycin sulphate & $20 \cdot 0$ & pet & $1(0.8)$ & $1(1 \cdot 6)$ & NS \\
\hline Quinoline mix & $6 \cdot 0$ & pet & $1(0 \cdot 8)$ & $0(0)$ & NS \\
\hline Parabens & $15 \cdot 0$ & pet & $1(0 \cdot 8)$ & $0(0)$ & NS \\
\hline Black rubber mix & 0.6 & pet & $1(0.8)$ & $0(0)$ & NS \\
\hline Metacapto mix & $2 \cdot 0$ & pet & $1(0 \cdot 8)$ & $0(0)$ & NS \\
\hline Thiuram mix & $1 \cdot 0$ & pet & $0(0)$ & $1(1 \cdot 59)$ & NS \\
\hline
\end{tabular}

pet $=$ Petrolatum; aq $=$ aqueous .

None of the farmers nor the printers had positive reaction to para-phenylenediamine (PPD), benzocaine, 4-tert-butylphenol formaldehyde, ethylenediamine dihydrochloride, Quaternium 15, Primin, Kathon CG, or wool alcohols.

Table 7 Skin sensitisation in farmers and controls (printers) to agricultural chemical test agents (comparisons were by $\chi^{2}$ test)

\begin{tabular}{|c|c|c|c|c|c|}
\hline Test compound & $\begin{array}{l}\text { Concentration } \\
(\%) \\
(w / w)\end{array}$ & Vehicle & $\begin{array}{l}\text { Sensitised } \\
\text { farmers } \\
\text { total } n=122 \\
n(\%)\end{array}$ & $\begin{array}{l}\text { Sensitised } \\
\text { controls } \\
\text { total } n=63 \\
n(\%)\end{array}$ & $P$ value \\
\hline Captofol (difolatan) & $0 \cdot 1$ & pet & $22(18 \cdot 0)$ & $3(4 \cdot 8)$ & 0.01 \\
\hline Folpet (phaltan) & $0 \cdot 1$ & pet & $13(10 \cdot 7)$ & $5(7 \cdot 9)$ & NS \\
\hline Captan & 0.5 & pet & $11(9 \cdot 0)$ & $5(7.9)$ & NS \\
\hline Benzalkonium chloride & $0 \cdot 1$ & aq & $7(5 \cdot 7)$ & $6(9 \cdot 5)$ & NS \\
\hline Benzyl peroxide & $1 \cdot 0$ & pet & $5(4 \cdot 1)$ & $1(1 \cdot 6)$ & NS \\
\hline Phenylmercuric acetate & 0.01 & $\mathrm{aq}$ & $4(3 \cdot 3)$ & $0(0)$ & NS \\
\hline Mercuric ammonium & 1.0 & pet & $4(3 \cdot 3)$ & $2(3 \cdot 2)$ & NS \\
\hline Dibrom & 0.01 & pet & $4(3 \cdot 3)$ & $0(0)$ & NS \\
\hline Nitrofurazone & 1.0 & pet & $3(2 \cdot 5)$ & $0(0)$ & NS \\
\hline Dodecyl gallate & $0 \cdot 25$ & pet & $3(2 \cdot 5)$ & $0(0)$ & NS \\
\hline Thimerosal & $0 \cdot 1$ & pet & $2(1 \cdot 6)$ & $1(1 \cdot 6)$ & NS \\
\hline Chlorhexidine digluconate & 0.5 & aq & $2(1 \cdot 6)$ & $0(0)$ & NS \\
\hline Parathion & 0.01 & $\mathrm{aq}$ & $1(0.8)$ & $1(1 \cdot 6)$ & NS \\
\hline Tylosin tartrate & $5 \cdot 0$ & pet & $1(0.8)$ & $0(0)$ & NS \\
\hline Malathion & 0.5 & pet & $1(0.8)$ & $0(0)$ & NS \\
\hline Ziram & $1 \cdot 0$ & pet & $1(0.8)$ & $0(0)$ & NS \\
\hline Gentamicin sulphate & $20 \cdot 0$ & pet & $1(0.8)$ & $0(0)$ & NS \\
\hline Alantolactone & 0.1 & pet & $0(0)$ & $1(1 \cdot 6)$ & NS \\
\hline
\end{tabular}

pet $=$ Petrolatum; aq $=$ aqueoous

None of the farmers nor the printers had positive reaction to Carbaryl, Zineb, Diethoate, Maneb, Paraquat, Pyrethrum, Benomyl, copper sulphate, 2-mercaptobenzathiazole.
$10 \%$ of farmers. Forty $(32 \cdot 8 \%)$ farmers reported skin discomfort especially on any contaminated sites at or after spraying. Table 5 shows the location of the skin disorders. On physical examination, pigmentation and thickening were mainly on the dorsal surface. A total of $37(30.3 \%)$ of our subjects had dermatitis of the hand. Dermatitis was seen mainly on volar fingers and palms, and was more prevalent on the right hand. A moderate prevalence of fungal skin diseases was also present (table 5). Table 6 shows the positive results of patch tests in the farmers and the printing press workers for the European standard tray and table 7 for agricultural chemicals. In the tests for individual agents, farmers had significantly more positive results for Captofol, and the printing press workers had more sensitisation to nickel sulphate. For the standard tray, similar proportions of the farmers and printing press workers had at least one positive result. For the agricultural chemicals tray, a significantly higher percentage of farmers had at least one positive result (table 8). Skin diseases in farmers were compared with results of patch testing. Among the 18 farmers with volar finger dermatitis 10 had at least one reaction to the patch agents; among the 15 with palm dermatitis nine had at least one reaction; among the seven with dorsal finger dermatitis four had at least one reaction; and among the six with dorsal hand dermatitis four had at least one reaction. Skin sensitivity to Captofol, Folpet, and Captan was associated with dermatitis in the volar aspect of the hand (table 9).

\section{Discussion}

This is the first article describing the prevalence of skin problems and skin sensitivity to patch testing agents among farmers in Taiwan. We found that fruit farmers had a high prevalence of skin changes such as pigmentation and thickening that were likely to be due to exposure to sun light, heavy manual work, and frequent minor traumas. About one third of the farmers also had dermatitis which could be partially explained by sensitivity to the skin allergens in the agricultural chemicals or ingredients in their gloves.

Fruit farmers in southern Taiwan work in rather small areas of land (the subjects in this study had an average 3.5 hectares for each household). The production of fruit is heavily dependent on the amount of pesticides used. Mostly the owners of the land in our study

Table 8 Farmers and their controls with at least one allergic reaction to the test agents (comparisons made by $\chi^{2}$ test)

\begin{tabular}{llll}
\hline & $\begin{array}{l}\text { Farmers } \\
\text { total }=122 \\
n(\%)\end{array}$ & $\begin{array}{l}\text { Controls } \\
\text { total }=63 \\
n(\%)\end{array}$ & $\begin{array}{l}P \\
\text { value }\end{array}$ \\
\hline $\begin{array}{l}\text { Standard tray } \\
(23 \text { agents) }\end{array}$ & $30(23 \cdot 8)$ & $15(24 \cdot 6)$ & NS \\
$\begin{array}{l}\text { Agricultural } \\
\text { chemical tray }\end{array}$ & $49(40 \cdot 2)$ & $12(19 \cdot 0)$ & 0.004 \\
\hline \begin{tabular}{l}
$(27$ agents) \\
\hline
\end{tabular}
\end{tabular}


Table 9 Relation between positive patch test results and dermatitis at different sites in subjects with or without dermatitis $n(\%)$

\begin{tabular}{|c|c|c|c|c|c|c|c|c|c|}
\hline \multirow{2}{*}{$\begin{array}{l}\text { Allergens } \\
\text { patch test } \\
\text { results }\end{array}$} & \multicolumn{3}{|l|}{ Captofol } & \multicolumn{3}{|l|}{ Folpet } & \multicolumn{3}{|l|}{ Captan } \\
\hline & no & yes & $P$ value & no & yes & Pvalue & no & yes & Pvalue \\
\hline \multicolumn{10}{|l|}{ Volar finger dermatitis } \\
\hline $\begin{array}{l}\text { No } \\
\text { Yes }\end{array}$ & $\begin{array}{l}88(88) \\
12(12)\end{array}$ & $\begin{array}{r}16(72 \cdot 7) \\
6(27 \cdot 3)\end{array}$ & 0.067 & $\begin{array}{l}95(87 \cdot 2) \\
14(12 \cdot 8)\end{array}$ & $\begin{array}{l}9(69 \cdot 2) \\
4(30 \cdot 8)\end{array}$ & 0.085 & $\begin{array}{l}97(87 \cdot 4) \\
14(12 \cdot 6)\end{array}$ & $\begin{array}{l}7(63 \cdot 6) \\
4(36 \cdot 4)\end{array}$ & 0.034 \\
\hline \multicolumn{10}{|l|}{ Volar palm dermatitis } \\
\hline $\begin{array}{l}\text { No } \\
\text { Yes }\end{array}$ & $\begin{array}{l}88(88) \\
12(12)\end{array}$ & $\begin{array}{r}19(86 \cdot 4) \\
3(13 \cdot 6)\end{array}$ & NS & $\begin{array}{l}99(90 \cdot 8) \\
10(9 \cdot 2)\end{array}$ & $\begin{array}{l}8(61 \cdot 5) \\
5(38 \cdot 5)\end{array}$ & 0.0024 & $\begin{array}{l}98(88 \cdot 3) \\
13(11 \cdot 7)\end{array}$ & $\begin{array}{l}9(81 \cdot 8) \\
2(18 \cdot 2)\end{array}$ & NS \\
\hline \multicolumn{10}{|l|}{ Dorsal finger dermatitis } \\
\hline $\begin{array}{l}\text { No } \\
\text { Yes }\end{array}$ & $\begin{array}{c}95(95) \\
5(5)\end{array}$ & $\begin{array}{r}19(86 \cdot 4) \\
3(13 \cdot 6)\end{array}$ & NS & $\begin{array}{c}101(92 \cdot 7) \\
8(7 \cdot 3)\end{array}$ & $\begin{array}{c}13(100) \\
0(0)\end{array}$ & NS & $\begin{array}{c}104(93 \cdot 7) \\
7(6 \cdot 3)\end{array}$ & $\begin{array}{c}10(90 \cdot 9) \\
1(9 \cdot 1)\end{array}$ & NS \\
\hline \multicolumn{10}{|l|}{ Dorsal hand dermatitis } \\
\hline $\begin{array}{l}\text { No } \\
\text { Yes }\end{array}$ & $\begin{array}{c}95(95) \\
5(5)\end{array}$ & $\begin{array}{c}21(95 \cdot 5) \\
1(4 \cdot 5)\end{array}$ & NS & $\begin{array}{c}104(95 \cdot 4) \\
5(4 \cdot 6)\end{array}$ & $\begin{array}{c}12(92 \cdot 3) \\
1(7 \cdot 7)\end{array}$ & NS & $\begin{array}{c}106(95 \cdot 5) \\
5(4 \cdot 5)\end{array}$ & $\begin{array}{c}10(90 \cdot 9) \\
1(9 \cdot 1)\end{array}$ & NS \\
\hline Total & 100 & 22 & & 109 & 13 & & 111 & 11 & \\
\hline
\end{tabular}

prepared and applied and sprayed the pesticides. None of our subjects used a spraying machine. A considerable proportion of farmers did not wear adequate protective clothing (table 3) mainly due to discomfort or perceived interference with the work (data not shown). Close contact and skin exposure to agricultural chemicals were therefore expected in these working conditions.

Our examination found that the farmers had a moderate prevalence of dermatitis (30.3\% had dermatitis of the hand). Among them, slightly more than a half had a reaction to at least one patch agent. Although sensitivity to patch agents did not necessarily indicate an allergic aetiology of the dermatitis, allergic and irritant causes might each contribute to a significant proportion of contact dermatitis in our subjects. The exact percentage of each, however, could not be measured by this investigation.

The farmers had a high prevalence of skin reaction to Captofol, Folpet, and Captan. Although Captofol was banned as a pesticide in 1988, and Folpet and Captan were banned in 1990 in Taiwan, use of Captofol and Captan was volunteered by the farmers, mostly under different brand names. Also, three of the farmers reported having skin discomfort after spraying Captofol. It was likely that the use of these agricultural chemicals was underreported when the farmers were interviewed. Captofol (cis- $\mathrm{N}-((1,1,2,2-$ tetrachloroethyl)thio)-4-cyclohexene-1,2-dicarboximide), Folpet (N-(trichloromethyl)thiophthalimide), and Captan (N-(trichloromethyl)thio-4-cyclohexene-1,2-dicarboximide) are structurally similar and belong to the same group of thiophthalimides. Cross reaction might exist between these chemicals. In the 22 farmers sensitive to Captofol, six $(27 \cdot 3 \%)$ were sensitive to Folpet, and six $(27 \cdot 3 \%)$ were sensitive to Captan; compared with $7 \%$ to Folpet and 5\% to Captan in those not sensitive to Captofol. In the 13 farmers sensitive to Folpet, eight $(61.5 \%)$ were sensitive to Captan compared with $2 \cdot 8 \%$ in those not sensitive to Folpet. The prevalence of sensitivity to Captan was not clear in the Taiwanese general population. However, in our previous studies on hairdressers, about $6 \%$ of hairdressers were sensitive to Captan. ${ }^{5}$ In this investigation, five $(7.9 \%)$ of the 63 printing press workers were sensitive to both Captan and Folpet simultaneously, and three of these five subjects were sensitive to Captofol. Captofol is a fungicide reported as causing allergic dermatitis in farm workers $^{67}$ and workers in the timber industry. ${ }^{8}$ Folpet was also known as an agricultural contact allergen. However, in western literature the prevalence of sensitivity to these two agricultural chemicals was low ${ }^{10}$ compared with this study. In a Japanese study, a similar rate $(28.7 \%)$ of sensitivity to Captofol as in this investigation was reported. ${ }^{11}$ Frequency of use and contact, and genetic predisposition might have contributed to this observed difference between eastern and western studies. Skin sensitivity to Captofol, Folpet, and Captan was significantly associated with clinical findings of dermatitis, especially on the volar surface of the hand. This finding indicated that sensitivity to these agricultural chemicals was clinically significant in inducing skin diseases, and that some sensitised fruit farmers might have been actively exposed to these chemicals during the period of our investigation.

Farmers and printing press workers had similar rates of sensitivity to ingredients of their gloves, indicating the possibility of a similar proportion of glove use in these two industries. Reactions to benzalkonium chloride was similarly high in our farmer and printer groups. Benzalkonium chloride is widely used as a disinfectant, and is present in many cosmetics, mouthwashes, dentifrices, ophthalmic preparations, and deodorants. It is used industrially in both printing presses and agriculture and was known to cause allergic contact dermatitis. ${ }^{12}$ Phenylmercuric salts were used as herbicides and agricultural fungicides and were reported to cause contact dermatitis. Only $3.3 \%$ of our farmer subjects were sensitive to phenylmercuric acetate. Neomycin is known to cause sensitisation in vetinarians and farmers who frequently handle domestic animals. ${ }^{13}$ Because handling animals was not a common practice of fruit farmers, a low prevalence of sensitivity to neomycin in our subjects was expected. Although reactions to nickel are rather common in women, especially those with pierced ears, nickel sensitivity in men 
could be limited to specific working groups, not including farmers. The low prevalence of nickel reactions in our subjects was therefore expected. Higher prevalence in printing press workers was likely to be due to a higher percentage of women in that group. We did not find positive reactions to benomyl, a pesticide that is known to cause contact dermatitis, ${ }^{1415}$ but is not widely sold in Taiwan.

The subjects in this study were selected from the Fruit Farmers' Production Association, members of which were interested in promoting the production and sales of their fruits. It is possible that they represented a group of farmers who were more careful about the use of pesticides than the general population. Therefore, we might be biased towards having a group of farmers who were less exposed and less affected by the pesticides than the general population of fruit farmers in southern Taiwan.

We conclude that fruit farmers in southern Taiwan were exposed to pesticides during their work from heavy use and less than optimal protection. Contact dermatitis and fungal infection were seen in some farmers, and pigmentation and thickening of the skin were prevalent. Farmers were more likely than printing press workers to have skin sensitivity to agricultural chemicals, and this allergy was associated with clinical findings of dermatitis.
This investigation was supported by grant No DOH 84-HR213 from the Department of Health, Taiwan, Republic of China.

1 Mathias CGT. Epidemiological aspects of occupational skin disease in agriculture. In: Dosman JR, Cockroft D, eds. Principles of health and safety in agriculture. Boca Raton: CRC press;1989:285-7.

2 Maddy KT, Edmiston S, Richmond D. Illness, injuries, and deaths from pesticides exposures in California and deaths from pesticides exposures in California 3 Lin MS, Chou SY, Guo NW, Lai ML, Guo YL. Pesticide use and neurological effects in fruit farmers. Chinese $f$ Public Health 1995;14:392-9. (In Chinese, with English abstract.)

4 Hannuksela M. Epicutaneous testing. Allergy 1979;34:5-10.

5 Guo YL, Wang BJ, Lee YY, Chou SY. Occupational hand dermatoses of hairdressers in Tainan City. Occup Environ Med 1994;51:689-92.

6 Peoples SA, Meddy KT, Tochilin S, Edmiston S. Human health problems associated with exposure to the fungicide captofol (Difolatan) in California. Vet Human Toxicol 1978;20:184-9.

7 Matsushita T, Nomura S, Wakatsuki I. Epidemiology of contact dermatitis from pesticides in Japan. Contact

8 Stoke JCJ. Captofol dermatitis in the timber industry. Contact Dermatitis 1979;5:284-92.

9 Lisi P, Caraffini S, Assalve D. A test series for pesticide dermatitis. Contact Dermatitis 1986;15:266-9.

10 Lisi P, Caraffini S, Assalve D. Irritation and sensitization potential of pesticides. Contact Dermatitis 1987;17:212-8.

11 Matsushita T, Nomura S, Wakatsuki T. Epidemiology of contact dermatitis from pesticides in Japan. Contact Dermatitis 1980;6:255-9.

12 Fisher AA, Stillman MA. Allergic contact sensitivity to benzalkonium chloride (BAK). Cutaneous, ophthalmic, benzalkonium chloride (BAK). Cutaneous, ophthalmic, and general

13 Neldner KH. Contact dermatitis from animal feed additives. Arch Dermatol 1972;106:722-3.

14 Ketel van WG. Sensitivity to the pesticide benomyl. Contact Dermatitis 1976;2:290-1.

15 Joost van TH, Naafs B, Ketel van WG. Sensitization to benomyl and related pesticides. Contact Dermatitis 1983; 9:153-4.

\section{Occupational and Environmental Medicine and the electronic age}

OEM has an Email address which is 100632.3615@compuserve.com. We welcome contact by Email, including letters to the editor. Some of our reviewers already send us their reports by Email, helping to speed up the peer review process.

We are moving towards electronic publishing and for some months now we have been asking authors to send us their revised papers on disk as well as a hard copy. I am delighted to report that nearly all our authors are managing to comply with this request; far more than for other specialist journals in the BMJ Publishing group. Oddly enough, the few authors who have not sent us a disk version of their revised papers have been almost exclusively from the United Kingdom. I would be interested in suggestions for why this might be. Perhaps United Kingdom based authors read our correspondence and instructions less assiduously? Watch for revised Instructions to Authors.

The Editor 